\title{
O Compahc de São Bernardo do Campo - No curso das políticas municipais de preservação
}

\section{The Compahc of São Bernardo do Campo - On the way of municipal preservation practices}

\author{
Marcelo Cardoso de Paiva \\ Historiador formado pela Faculdade de Filosofia, Letras e Ciências \\ Humanas da Universidade de São Paulo. \\ marcelo@apenas.com
}

\section{Resumo}

Este artigo é uma leitura da trajetória do Conselho Municipal do Patrimônio Histórico e Cultural de São Bernardo do Campo, o Compahc-SBC, analisando aspectos como a origem do órgão, seus critérios de atuação e suas medidas de preservação com ênfase na prática do tombamento à luz de uma discussão mais ampla sobre práticas de preservação do patrimônio cultural.

Palavras-chave: Patrimônio Histórico; Políticas Públicas; São Bernardo do Campo

\section{Abstract}

This article is an overview on the Historical and Cultural Heritage Municipal Council of São Bernardo do Campo, the CompahcSBC, by analysis of aspects such its birth, its standards of action and preservation arrangements under the light of a wider discussion about Cultural Heritage Preservation Practices.

Keywords: Historical heritage; Public policy; São Bernardo do Campo 
1 - Este artigo foi escrito como resultado do trabalho final da disciplina Políticas Públicas de Preservação do Patrimônio Cultural Edificado no Brasil sob orientação dos professores doutores Anna Lúcia Duarte Lanna e Paulo César Garcez Marins na pós-graduação da FAU-USP, cursada pelo autor.

2 - Informações detalhadas sobre cada bem tombado, textos de decretose leis e outras informações relevantes sobre Compahc estão disponíveis na internet na página da Secretaria de Educação e Cultura no site oficial da Prefeitura Municipal de São Bernardo do Campo www.saobernardodocampo.sp.gov.b.

3 -São elas Educação e Cultura, Assuntos Jurídicos, Obras, Planejamento e Tecnologia da Informação, Desenvolvimento Econômico e Turismo, Habitação e Meio Ambiente, Esportes e Serviços Urbanos. Soma-se às elas a Seção de Memória e Patrimônio.

4 - OAB-SBC, Universidade Metodista de São Paulo, Diretoria de Ensino da região de $S B C$, Associação dos Engenheiros e Arquitetos de SBC, Instituto do Patrimônio do $A B C$, Ecojuris - núcleo sobre meio ambiente, Associação dos Artistas e Artesãos de SBC, Gipem (Grupo Independente de Pesquisadores da Memória do Grande $A B C$ ), Terra Viva-movimento de resistência ecológica e SOS Chácara Silvestre.
7 ação dos poderes públicos municipais sobre a preservação do patrimônio histórico e cultural tem sido cada vez mais intensa e relevante nas últimas décadas. Isso se deve pelo fato de que os poderes públicos municipais herdaram o desafio de enfrentar questóes e tensóes sociais inerentes ao patrimônio não resolvidas ou sequer contempladas por órgãos de preservação federais e estaduais. Assim, é por meio deles que se torna mais nítido o enfrentamento de diversas forças sociais que caracterizam o patrimônio como um qualificado espaço de poder. Por essas razóes se faz bastante relevante o estudo ainda escasso da atividade dos órgãos municipais de preservação [1].

O Compahc, Conselho Municipal do Patrimônio Histórico e Cultural de São Bernardo do Campo, existe desde 1984, vinculado à Secretaria de Educação e Cultura e assessorado oficialmente pelo Serviço de Patrimônio Histórico da cidade. Até hoje vinte e um bens edificados foram tombados e mais de cem outros bens estão em estudo para definição de seu grau de proteção[2]. O inventário faz parte das Diretrizes para a Proteçáo do Patrimônio Cultural, documento emitido em 2002 que define uma política de atuação para o órgão. O Compahc atua através de um colegiado de vinte membros sendo nove representantes de secretarias municipais[3], dez representantes de organizaçôes da sociedade civil[4] e um historiador, todos com mandato de dois anos. Partindo da consulta do Livro de Atas e do Livro Tombo do Compahc, leis, decretos, jornais e publicaçóes, busco fazer aqui uma leitura da trajetória do Compahc até o início da década de 2000 à luz de uma reflexão mais ampla sobre práticas de preservação do patrimônio histórico e cultural.

A escolha do município de Sáo Bernardo do Campo para a discussão se deve não só pelo pioneirismo e experiência do Compahc como também pela particularidade de seu processo histórico essencialmente industrial caracterizado por significativas ondas migratórias (estrangeiras e nacionais), movimentos sociais e políticos de proporçóes nacionais e intensa transformação de sua paisagem urbana (um sério desafio para preservação do patrimônio). Esses aspectos fazem da experiência do município na preservação de bens culturais um objeto interessante de reflexão.

O município de Sáo Bernardo do Campo surge em 1944 emancipado do atual município de Santo André. A preocupação do poder público municipal com o patrimônio cultural aparece pela primeira vez em 1969 quando, por via do via decreto-lei municipal No9 de 1969, nove bens imóveis são arrolados sendo eles quatro capelas, uma igreja (todas católicas), três casas e a primeira igreja presbiteriana da cidade.

Ao longo da década de 1970, servidores públicos municipais da região teceram açóes no sentido de preservação da memória regional mobilizando a população. Em 1976 em Santo André foi realizada uma campanha pública que recolhia junto à comunidade suportes de memória que deu origem em 1981 ao atual Museu de Santo André, que hoje reúne um rico acervo com fotografias, hemeroteca e objetos sobre a história da região desde o século XIX. Em São Bernardo do Campo, na mesma época, funcionários da Divisão de Biblioteca tiveram iniciativa semelhante recolhendo diversas contribuições dos cidadãos bernardenses (incluindo registros de patrimônio imaterial) para compor o que deram o nome de Sala Sáo Bernardo. O acervo recolhido hoje compóe um centro de cultura popular e folclore sobre a cidade. Ao início da década de 1980 grupos independentes da sociedade civil como o jornal Diário do Grande $A B C$ e o Gi- 
pem (Grupo Independente de Pesquisadores da Memória) também promoviam a defesa do patrimônio cultural de diversas maneiras.

Em 1975 a prefeitura de São Bernardo do Campo lança o Projeto Lorena (TOLEDO, 1975), um ambicioso plano de revitalização da Calçada do Lorena e outros caminhos da Serra do Mar bem como os monumentos nelas existentes. Foram contemplados no Projeto Lorena caminhos em torno dos quais o Grande ABC (ou mais especificamente São Bernardo do Campo) se estabeleceu: Caminho do Padre José (de Anchieta, século XVI), a Estrada do Lorena (final do XVIII), A Estada da Maioridade (meados do XIX), a Estrada do Vergueiro (segunda metade do XIX), o Caminho do Mar (década de 1910) que ligavam Santos à capital, e os monumentos da Serra concebidos por Victor Dubugras na década de 1920 por encomenda do então Presidente do Estado de São Paulo Washington Luís. Ao Professor Benedito de Lima de Toledo da FAU-USP coube a autoria e coordenação do mega-projeto que previa a instalaçáo de um grande parque turístico e também a preservação ambiental da Serra do Mar envolvendo diversas empresas. A iniciativa da prefeitura rendeu medidas protetoras do Condephaat que em 1979 tombou o conjunto[5]. Entretanto o Projeto Lorena não aconteceu e a revitalização do conjunto só foi iniciada na década de 1990 patrocinada pela Eletropaulo sendo o parque aberto à visitação apenas em 2004. O Compahc e a prefeitura náo participaram do processo exceto prestando consultorias isoladas no fim da década de 1980 .

No entanto, a idéia de uma ação pela preservação do conjunto histórico e natural da Serra do Mar amparada pelo Condephaat parece muito ter mobilizado a sociedade e seus representantes para a preservação do patrimônio histórico e cultural na regiáo. Somado a isso, em 1981, o incêndio que atingiu o prédio da antiga estação ferroviária Alto da Serra na vila histórica de Paranapiacaba tornou clara e urgente a necessidade de uma ação pela defesa do patrimônio no ABC. $\mathrm{O}$ momento propiciava a discussão. Em 1982, o jornal Diário do Grande ABC alerta sobre o risco de demoliçóes das estaçóes ferroviárias. Em novembro do mesmo ano, o jornal diz que o projeto de lei que cria o Compahc estava finalizado. Em 1983, em São Bernardo do Campo, há uma mobilização social contra a venda do imóvel dos Estúdios Cinematográficos Vera Cruz e, segundo o jornal, a principal motivação para a abertura oficial do Compahc foi a demolição, no início de 1984, de um casarão na rua Marechal Deodoro listado como bem de interesse (talvez entre os arrolamentos de 1969)[6]. A demolição da casa, que possuía um título assinado por Bernardino de Campos em 1895, ocorreu, apesar dos esforços pela preservação e de embargada pela prefeitura.

Simultaneamente, aqueles servidores ligados à Divisão de Biblioteca se mobilizavam contra a iniciativa da prefeitura de incinerar os documentos oficiais originais após o processo de microfilmagem iniciado em 1979. Sensíveis também às manifestaçóes públicas, começaram a promover a ideia de um órgão oficial para tratar da preservaçáo do patrimônio cultural na forma de conselho aproveitando o material do arquivo oficial não incinerado como fonte de pesquisa para tombamentos. Em 26 de junho de 1984, após estudos e anteprojetos, é então criado o Compahc através da Lei Municipal 2.608.

O primeiro presidente do Conselho foi Enrique Ricardo Lewandowski, que assumiu o cargo de Ministro do STF em 2006 e à época era Secretário de Governo e de Assuntos Jurídicos da Prefeitura Municipal de São Bernardo. Sua gestão trouxe a colaboração da Emplasa nos procedimentos de levantamento
5 - Inscrição №122, p.21 do Livro Tombo Histórico do CONDEPHAAT, disponível para consulta na internet.

6 - Consultar o jornal Diário do Grande $\mathrm{ABC}$ principalmente as edições de 11/03/1982, 06/11/1982 e 08/08/1985. 


\section{Artigos \& Ensaios}

7 - Consultar Lei Municipal № 2611 da Prefeitura de São Bernardo do Campo, Art 2 18/06/1984;

8 - Consultar Livro de Atas do Compahc, 5 a Reunião Ordinária, 03/06/1986; para inventários de bens culturais e do Sphan e do Condephaat através de Antonio das Neves Gameiro, e Adauto Moraes, respectivamente, para elaboração de regimento interno. Os primeiros conselheiros eram de seis secretarias municipais e membros da Associação dos Engenheiros e Arquitetos do ABC, da Cúria Metropolitana de São Paulo e do Instituto Histórico e Geográfico de São Paulo, um procurador judicial, um arquiteto e um historiador.

\section{Primeiros ENSAIOS, PRIMEIROS TOMBAMENTOS}

Antes mesmo do início das atividades do Compahc a Câmara Municipal decretou que "Os bens arrolados [no Decreto-Lei No9 de 1969] seráo objeto de futuro tombamento"[7]. Tão logo ativo, o Conselho decidiu que "os bens imóveis já arrolados por Lei sejam tombados mediante o levantamento e reconhecimento histórico"[8]. Estavam definidos os primeiros tombamentos.

Dentre esses bens, alguns já contavam com apelo popular como a Capela de Santo Antônio e a Casa do Esporte (atual câmara de cultura). Alguns conselheiros ainda visitaram pontos de interesse ao longo das atuais Avenida Rudge Ramos, Rua Vergueiro, Avenida Marechal Deodoro, Via Anchieta e Caminho do Mar chegando à Serra, percurso que coincide com os antigos caminhos que ligavam Santos à capital, hoje situados em perímetro urbano.

As primeiras açóes parecem náo ter fugido do "caminho seguro" herdado da "fase heróica" do IPHAN na medida em que priorizaram o tombamento de bens isolados e de caráter excepcional, embora alguns estivessem vinculados à imigraçáo, algo tradicionalmente ignorado pelo órgáo federal. A maior parte dos tombamentos prendeu-se ao eixo dos velhos caminhos da Serra do Mar, o que os remetia de alguma forma aos espaços gerados no período colonial e imperial, aos caminhos por onde D.Pedro I e D.Pedro II passaram em missão oficial, a fatos importantes para a história da administração pública do município, ou ainda de igrejas com relíquias trazidas da Europa por imigrantes.

A Capela N.Sra da Boa Viagem, no centro da cidade, por exemplo era ponto de parada para viajantes entre capital e porto. A Casa do Esporte (primeira câmara municipal do $\mathrm{ABC}$ e gabinete de vários prefeitos), a Chácara Silvestre (residência de veraneio do primeiro prefeito da cidade Wallace Simonsen, também responsável pela emancipação política do município) e a Casa do Comissário do Café evidenciam escolhas sobre a formação do governo municipal e de personalidades de destaque político e econômico.

Por outro lado, manifestaçôes sociais levantaram novas sugestóes de tombamento, sendo em grande parte defendidas pelos conselheiros Bruno Corazza, engenheiro, e Ademir Médici, historiador. Foram entáo tombados em 1987 o prédio Alfa da Universidade Metodista de 1942 e os Estúdios da Cia Cinematográfica Vera Cruz, terceira companhia cinematográfica brasileira criada em 1949 por Ciccilo Matarazzo e Franco Zampari. A Vera Cruz deu projeção ao cinema nacional com filmes premiados como Sinhá Moça e $O$ Cangaceiro, entrou em crise financeira e encerrou suas atividades em 1972.

Com forte apoio da sociedade, este foi o primeiro tombamento a contemplar a característica transformação industrial e econômica da cidade no século XX. Atento a isso, Corazza ainda propôs a preservação da chaminé da Cerâmica Garcez e a Torre da Elni, uma estaçáo de tratamento de água para alvejamento de fios de uma tecelagem, ambas da década de 1940. O tombamento da Torre da Elni foi vetado pelo prefeito a pedido do Secretário de Obras que tinha planos de 
ocupar a área com um estacionamento para o estádio municipal que estava em construção no local. A torre só chegou a ser tombada em 1999.

Em 1989, ao fim da primeira gestão, o prefeito Maurício Soares pede revisão do regimento interno para inclusão de mais setores da prefeitura. Desde então não há registros de reunióes do Compahc até 1993, embora em 1990 tenha sido publicada a Lei 3.496 tombando a Cidade da Criança, construída em 1968 como cenário da novela Redenção da extinta TV Excelsior.

A despeito desse hiato, cresce o debate acerca da preservação do patrimônio histórico e cultural no grande ABC nos anos seguintes. A Prefeitura Municipal de São Bernardo do Campo realizou através do Serviço de Documentação da História Local (que desde 1988 suprira o serviço técnico do Compahc) o II Congresso de História do Grande ABC: Caminhos e Rumos: Índios, escravos e operários em 1992 no qual se discutiu a conjuntura do patrimônio da região e vários especialistas colocaram à prova a atuação dos órgãos de preservação[9]. O município de Santo André acabara de criar o Condephaapasa, seu conselho de defesa do patrimônio e São Caetano do Sul a Fundação Pró-Memória, uma autarquia responsável pela proteção do patrimônio da cidade.

\section{As CIRCUNSTÂNCIAS DESENHAM AS POLÍTICAS}

O prefeito Walter Demarchi convoca a reabertura do Compahc em 1983. Conrado Bruno Corazza, representando a Associação dos Engenheiros e Arquitetos do ABC, é eleito presidente do Conselho por unanimidade. À nova gestão se impunham diversos desafios: zelar pelos bens tombados, compor um corpo técnico e se estabelecer perante administração pública e sociedade. Se nos primeiros anos se fez uso do tombamento como um fim, agora se apresentava a necessidade de se encontrar vias mais efetivas de preservação.

A gestáo de Bruno Coraza foi conduzida por circunstancialidades e urgências. Por um lado a má conservação e o abandono em que se encontravam os bens protegidos já eram por si só temerários. Por outro, roubos, arrombamentos, depredação e até ocupações, atestavam que o destino dos bens tombados era a questáo mais urgente a ser tratada. Outro problema que engessava o Compahc era a impopularidade do tombamento que causava demoliçôes e vendas de bens de interesse mais rapidamente do que processo jurídico de proteção conseguia agir.

Os problemas eram vários: a reforma em andamento na Capela Santo Antônio trazia o risco de descaracterização; a população pedia reabertura da Capela de São Bartolomeu para realização de missas dominicais; a Casa do Esporte fora invadida e ocupada e sua recuperação fora iniciada sem o aval do Compahc, o SDHL fez um levantamento dos monumentos da cidade que necessitavam de cuidados mais urgentes e o tombamento da casa à Praça Samuel Sabatini que abrigou o primeiro ginásio da cidade fora revogado em decorrência da demolição do bem para venda do terreno[10]. Em seguida o Conselho se uniu também à população agindo em defesa da preservação do terreno das antigas Indústrias Matarazzo, última área verde do centro da cidade, de propriedade do Ministério da Previdência Social, que estava sendo pouco a pouco devastada. Mesmo enviando ofícios e buscando resultados junto ao Prefeito Walter Demarchi, ao Ministro da Previdência Antônio Brito, ao Ibama e até ao Presidente da República Itamar Franco, o Compahc, impotente assiste ao loteamento e venda da área.

Em 1995 a nova gestão assume o Compahc sob a presidência de Augusto
9 - As transcrições das mesas-redondas do Congresso foram publicadas nos Anais do 20 Congresso de História da Região do Grande ABC - Prefeitura Municipal de São Bernardo do Campo, Secretaria de Educação e CulturaDepartamento de Ações Culturais, 2000.

10 - Lei Municipal 3455 de 08/02/1990 da Prefeitura Municipal de São Bernardo do Campo. 


\section{Artigos \& Ensaios}

11 - Livro de Atas do COMPAHC, 12ㅁ Reunião Extraordinária, 30 de junho de 1997.

12 - Livro de Atas do COMPAHC 6 Reunião Extraordinária, 25 de junho de 1996.
Frederico de Almeida que tomou como meta principal "definir a atuação política de preservação do patrimônio histórico do Compahc”[11]. Para tanto, Almeida buscou qualificação para os conselheiros promovendo cursos, estudos e parcerias com instituiçóes locais como a Universidade Metodista e também buscou apoio da USP, do Condephaat e do Iphan. Assim ficou claro que "O ideal é que o uso seja compatível com o tombamento servindo para atividades culturais"[12]. Concomitantemente o Compahc buscou fortalecer a relação e se sincronizar com outras secretarias municipais para viabilizar seus processos. Os resultados foram notáveis. Eventos envolvendo os bens culturais foram promovidos e incluídos na agenda cultural da cidade dando visibilidade ao patrimônio cultural. Esse conjunto de açôes reestruturou o Conselho, melhorou sua imagem pública e sua eficiência e acabou por lhe garantir novo fôlego.

Carolina Fusari, representante da $\mathrm{OAB}$, assume a presidência do Conselho em 1998 por ter boas relaçóes na prefeitura. Sua gestão foi marcada pelo amadurecimento do conceito do entorno do bem cultural, pela retomada do tombamento e pela parceria com a iniciativa privada para preservação e revitalização de alguns bens. Em 1999, a partir do SDHL é criado e regularizado o Serviço de Patrimônio Histórico e Cultural, sendo até hoje uma de suas atribuiçóes oficiais dar suporte técnico administrativo ao Compahc.

As novas propostas de tombamento passaram a contemplar a industrialização, bens naturais, paisagens e áreas envoltórias, por exemplo, as Indústrias Matarazzo na Vila Lusitânia e dez casas de sua antiga vila operária próximas ao centro da cidade, o Obelisco do Soldado Constitucionalista (monumento feito em 1982), alguns túmulos do Cemitério da Vila Euclides, a Torre da Elni (novamente), e a fonte de água mineral decorada com azulejos no bairro Baeta Neves. Até 2000 o Compahc demonstra intensa atividade no cenário político e social com maior divulgação de atividades, participaçóes em seminários, expansão da representatividade civil e secretarias municipais e ainda na manutenção dos bens tombados como o restauro da Capela de Santa Filomena após um incêndio e as reformas da Capela N.Sra. da Boa Viagem e da Igreja Presbiteriana cujo teto desabara.

Em abril de 1999, seis conselheiros na tentativa de estabelecer um fluxograma de tombamento mais eficiente acabaram por sistematizar a atuação do Conselho em comissóes técnicas: vistoria, assuntos jurídicos, arquitetura, história, educação, área envoltória e meio ambiente. Elas vigoram até hoje e incluem também conselheiros suplentes. Os mesmos seis conselheiros definiram como critérios de tombamento o sindicalismo, a industrialização, imigração/colônias, movimento migratório, urbanização e memória agrícola. Finalmente se esboçavam alguns critérios de atuaçáo que dotou o Compahc de uma eficiência sem precedentes elevada ainda mais na gestão seguinte quando Bruno Corazza retorna à Presidência do Conselho.

Em 2001, um workshop sobre patrimônio cultural com apoio de vários profissionais e do Ministério Público deu início a uma série de estudos e reunióes entre os conselheiros, culminando na elaboração do documento intitulado Diretrizes para a Proteção do Patrimônio Cultural, que determina a política de atuaçáo do Compahc. Nele se definem os critérios para tombamento, a ampliaçáo do conceito de patrimônio cultural incluindo diversas formas manifestaçóes de memória, o entendimento de bens naturais como objeto de ação cultural humana, o reconhecimento da diversidade e das tensóes sociais nas manifestaçóes de 
memória, o patrimônio imaterial, a representação civil no Conselho, a continuidade das açôes independente das flutuaçóes político-administrativas, e, acima de tudo, "considerar o patrimônio como um direito social fundamental"[13]. As Diretrizes organizaram a ação do Compahc em identificação (inventário), proteção física (definição do uso), proteção legal e divulgação. Politicamente o documento defende a democratizaçáo do patrimônio histórico e cultural e sua acessibilidade, as atribuiçóes do corpo técnico, a política de incentivos e a inserção do Conselho na política de planejamento urbano do governo municipal.

\section{Cidade e Patrimônio: e a experiência do Compahc e os Caminhos de PRESERVAÇÁO}

A história do Compahc apresenta um emaranhado de questôes dignas de reflexão dentro da discussão atual sobre práticas de preservação do patrimônio. A primeira que chama a atenção são os repertórios de bens culturais e a natureza das medidas de preservaçáo tomadas como tombamentos e inventário. A partir desses repertórios se coloca uma questão sobre a dimensáo política do Conselho: quem são os conselheiros, que grupos ou interesses sociais e políticos representam e em que medida influenciam esse repertório? Por fim resta a ampla reflexão sobre qual é o papel do Estado, na esfera municipal, no que diz respeito ao patrimônio e sua preservação.

Maria Cecília Londres Fonseca indica que "passam a se tornar viáveis tombamentos estaduais e municipais" em decorrência de uma "política pública fundada sobre o valor simbólico da nacionalidade e conduzida por uma instituição estatal que gozava de alto grau de autonomia em relação aos movimentos da sociedade" (FONSECA, 2005). Assim resta aos órgáos municipais contemplar em sua ação as tensões e dinâmicas que caracterizam a experiência histórica local.

O tombamento foi sempre tido pelo Compahc como principal e por vezes única medida de proteção dos bens culturais e continua sendo expressão máxima de sua ação. No entanto, o Conselho colidiu com demandas da sociedade bernardense por vezes completamente contrárias às suas próprias expectativas. $\mathrm{O}$ Compahc então se viu obrigado a considerar as formas de reapropriação do patrimônio cultural pelos cidadãos e, por isso, a necessidade urgente de ajustamento às demandas culturais da sociedade. Em outras palavras, embora "A ação desenvolvida pelos órgãos oficiais se realiza com variados graus de autonomia em relação à vontade política da sociedade" náo se exclui o fato de que "a 'preservação' do patrimônio cultural é, antes, prática social que acrescenta novos bens, valores e processos culturais à experiência da comunidade envolvida. Nesse sentido, ela é sempre uma forma de intervenção" (ARANTES, 1987).

Onze dos vinte e um bens tombados pelo Compahc foram registrados logo em sua primeira gestão. Destes, nove foram os bens arrolados pela prefeitura em 1969 e, seguindo a tradição do Iphan, não constituem mais do que um esboço um tanto monumental das primeiras ocupaçóes da cidade. Assim, à parte das experiências cotidianas e da memória coletiva, desde o início se tornaram difíceis de traduzir pela população. Não por acaso os bens tombados foram roubados, depredados e até ocupados e a ação do Conselho estancou na discussão da dificuldade em se tratar de tombamentos.

No início dos anos 90, os casos da perda da área verde das Indústrias Reunidas Matarazzo e da Casa à Praça Samuel Sabatini (já tombada), ambas no centro da cidade, mostram que o Compahc também enfrentou uma resistência
13 - Diretrizes para a Proteção do Patrimônio Cultural. Prefeitura de São Bernardo do Campo, Secretaria de Educação e Cultura, Compahc, 10 de abril de 2002; 
da própria administração pública municipal em reconhecer a legitimidade de sua ação. De acordo com Márcia Kersten,

A prática do tombamento, também uma intervenção humana, direciona as paisagens e o seu entorno alterando, substantivamente, seu significado, inventando uma tradição e uma história distinta às unidades tombadas. Desta perspectiva, pode ser definida como um instrumento de planejamento e de gestáo urbanística e ambiental (KERSTEN, 2000: 153)

Tendo isso em vista, o que qualifica a intervenção não pode ser o ato do tombamento, mas os efeitos que ela causará no cotidiano do espaço urbano enquanto planejamento e gestáo desse mesmo espaço e como se relacionará com a dinâmica da sociedade que o habita.

O Compahc precisou conquistar um lugar dentro do poder público a fim de obter legitimidade às suas medidas de preservaçáo. Para tanto, leva praticamente uma década para viabilizar novos tombamentos. Precisou para isso se focar numa via de mão-dupla entre a administração pública e as demandas da sociedade (organizada ou náo). Nesse processo, com o Inventário de Bens Culturais, criou recursos mais elaborados que definem diversos graus de preservaçáo, desde o simples registro até o tombamento, proporcionando assim maior flexibilidade nas suas medidas, como se confere na preservação do desenho urbano da Vila Caminho do Mar e de alguns aspectos do Cemitério da Vila Euclides, o mais antigo da cidade.

$\mathrm{Na}$ esteira desse aprendizado, as Diretrizes demonstram que o Conselho investiu tanto numa inserção mais ativa na agenda da administração pública quanto na contemplaçáo dos processos históricos mais latentes de transformação da cidade como critérios para a preservação. O documento ainda sinaliza maior abertura prevendo a preservação de bens "que são significativos e representativos da memória dos diversos grupos sociais que produziram o espaço da cidade"[14]. Ainda assim é muito desproporcional o número de tombamentos relacionados ao processo de industrialização, aos fluxos migratórios e aos movimentos operários característicos de São Bernardo do Campo. Há um longo caminho a se percorrer nesse sentido.

Isso só se possibilitará a partir da criação de canais mais sólidos de comunicação para participação mais ativa da sociedade e melhor conhecimento de suas demandas, que até o momento só chegam ao Compahc por via da atuação dos representantes de setores organizados da sociedade civil. No início eram quatro conselheiros hoje já somam dez.

Por essa razão, ainda está por se fazer um estudo sociológico cuidadoso sobre esses agentes dentro de conselhos. Quem são os conselheiros? Quais são as entidades que representam? Quais interesses os conduzem à preservação do patrimônio? Em que medida representam de fato diversos grupos sociais no Conselho? Sua participação que qualifica o Conselho como um espaço político onde tomam lugar tensôes sociais que se manifestam através do patrimônio. Nesse sentido, o próprio curso dos conselhos traz pistas para se compreender as dinâmicas de poder que transformam o espaço urbano hoje, logo, a própria história da cidade. Por isso o estudo e a reflexão sobre a atuação dos órgãos municipais de 
preservação e seus agentes são de grande pertinência.

Na história do Compahc fica claro o destaque individual de alguns conselheiros como Bruno Corazza, engenheiro representante da Associação de Engenheiros e Arquitetos de Sáo Bernardo do Campo. Corazza muito defendeu tombamentos relativos à industrialização (a Torre da Elni e a Chaminé na Av. Pery Ronchetti) e ainda contribuiu com idéias como a instalação de um Museu Industrial do Automóvel no prédio da Perkins (indústria de motores), afim com o processo industrial e econômico da cidade.

Simone Scifone, geógrafa representante da Universidade Metodista muito contribuiu para a consideração de bens naturais como patrimônio. A conselheira esteve à frente na defesa da fonte de água mineral do bairro Baeta Neves, um afloramento de lençol freático decorado com o painel de azulejos, e também da preservação da área verde no entorno da Chácara Silvestre, hoje a maior área verde da mancha urbana de São Bernardo do Campo. Scifone muito ajudou a viabilizar, por exemplo, o tombamento da Árvore dos Carvoeiros, de valor histórico e paisagístico situada à Via Anchieta, do Jatobá da rua Vergueiro e da área verde da Chácara Lauro Gomes.

Outro exemplo emblemático é a socióloga Doraci Sponchiato, supervisora do Serviço de Patrimônio Histórico do município (o serviço técnico do Compahc) e sua representante no Conselho. É em sua função que serviço técnico e deliberações do Conselho se encontram. A conselheira, junto com Simone Scifone e outros conselheiros, muito colaboraram na organização das comissóes técnicas e na elaboração das diretrizes. Além disso, Doraci Sponchiato estava entre os funcionários da Divisão de Biblioteca que na década de 70 tiveram a iniciativa da Sala São Bernardo que em contato com vários grupos sociais deu origem ao Centro de Pesquisa de Folclore e Cultura Popular, o que muito colaborou com o entendimento do Compahc sobre o patrimônio imaterial entre outros.

Por fim, qual é e qual deve ser o papel do Estado na definição de políticas de preservação do patrimônio? Para Marilena Chauí é papel do Estado subsidiar tecnicamente os movimentos sociais para a organização de suas próprias memórias e preservação de suas tradições e referências culturais em condiçóes de autonomia. Nesse sentido, o Estado, compreendido como serviço público, deve sobretudo servir, oferecendo recursos e respaldo para que os diversos grupos sociais elejam e preservem suas próprias referências. O trabalho dos especialistas em patrimônio deve ser de serviço técnico para que os movimentos sejam sujeitos e autores do trabalho memorialista.

No caso da preservaçáo do patrimônio, embora o tombamento seja competência exclusiva do poder executivo, os conselhos devem servir como agentes democráticos pelo reconhecimento e defesa do direito dos cidadáos à memória e à cultura, entendida por Chauí simultaneamente como fato ao qual temos direito como agentes ou sujeitos históricos e valor ao qual temos direito à criaçáo e à fruição, "procuramos assim (...) tornar inseparáveis cultura política e política cultural que buscam a democratização dos direitos” (CHAUÍ, 1992).

Evidentemente que o exercício de tais direitos pelos cidadãos na realidade são eclipsados por poderes atuantes na dinâmica do Estado. Esses mesmos poderes também interferem diretamente nas políticas de preservação de patrimônio por inúmeras razóes e interesses, especialmente quando envolvem capital e iniciativas privadas. Por conseguinte, os conselhos vagueiam no que Marly Rodrigues define como "o emaranhado das pressóes e dos limites político-administrativos 


\section{Artigos \& Ensaios}

15 - Livro de Atas do COMPAHC. 19a Reunião Ordinária, 4 de março de 1999. fls. 64 a 66 . e das discussóes dos critérios de atuação, esses elementos essenciais mas não suficientes para definir uma política de atuação" que, para a autora além de gerar "perdas inestimáveis ao patrimônio" cria uma imagem pública de ineficiência (RODRIGUES, 2000).

O Compahc em casos significativos foi de encontro aos interesses do poder político governante. Inicialmente para o tombamento da Torre da Elni já mencionada anteriormente, sofreu veto pelo prefeito a pedido do secretário de obras que viabilizava empreendimentos no local. Não muito tempo depois, mesmo contando com forte apoio popular, o Compahc náo consegue sucesso em proteger a área das Indústrias Reunidas Matarazzo criando aquela imagem pública de ineficiência apontada por Marly Rodrigues. Não sem esforço, o Conselho garante a preservação dos Estúdios Vera Cruz e evitar sua venda sendo a definição do seu uso uma questáo delicada ainda a ser resolvida.

O exemplo mais expressivo é o caso da área da Chácara Silvestre, um entrave entre Conselho e prefeitura que se arrasta desde 1999 quando foi aprovado um projeto de aproveitamento da área que inclui a instalação de "pistas de cooper, aparelhos de ginástica. local para eventos, infra-estrutura para recebimento do público (sanitários, bebedouros, etc)"[15] concessóes para restaurantes e vários outros serviços e também prevê a derrubada de centenas de árvores para a instalaçáo de uma escola ambiental. A sociedade se manifestou contra o projeto da prefeitura e o Compahc solicitou a revisão dos estudos que considerassem a máxima redução do impacto ambiental, menor descaracterização da área, e uso mais adequado com o valor do conjunto, negociação ainda longe de ser resolvida. A Chácara Silvestre, que abriga em seu casaráo o Centro de Pesquisa do Folclore e Cultura Popular desde 1984 e o material do Museu Histórico Pedagógico Raposo Tavares desde 1988, durante as negociaçóes ainda em andamento permanece fechada. $\mathrm{O}$ caso envolve o Compahc em uma séria problemática que surge como efeito do que Rogério Proença Leite define como:

políticas de gentrification, cujo resultado mais visível é a alteração da paisagem urbana, com a transformação de degradados sítios históricos em áreas de entretenimento urbano e consumo cultural (...) termo (...) aqui utilizado para designar a transformação dos significados de uma localidade histórica em segmento de mercado, considerando a apropriação cultural do espaço a partir do fluxo de capitais (...) que partem de uma concepçáo de mercado que implica uma gestão mista entre o Estado e iniciativa privada na forma de intervir no patrimônio como uma mercadoria cultural, cuja lógica altera o sentido político do lugar ao tomar o cidadáo como consumidor (LEITE, 2004: 19 a 21).

São vastas as várias outras questóes que podem ser abordadas a partir do estudo e análise da atuaçáo do Compahc e dos conselhos municipais de preservação, entre elas a consideraçáo do uso do patrimônio protegido como valor para preservação, ao que o Conselho bernardense tem se mostrado atento. Mas há ainda uma diversidade de valores e manifestaçôes culturais na sociedade que foge ao alcance desses órgãos. Por esse motivo o estudo de sua experiência muito 
contribui para a revisão de parâmetros, busca de referências e entendimento das práticas sociais inerentes ao patrimônio cultural. Por fim o Professor Ulpiano Toledo Bezerra de Menezes bem define a dimensão da questão do patrimônio cultural e sua preservação:

são os objetos, as coisas físicas. (...) inclusive, as paisagens, na medida em que elas são alteradas pela ação humana e apropriadas culturalmente. (...) É só o trabalho que constrói a realidade e a história outra coisa não é senão o fruto do trabalho do homem. Por isso mesmo, não é coincidência que só exista respeito pelo patrimônio Histórico quando também existe respeito pelo trabalho do homem. (MENEZES, 1980)

\section{REFERÊNCIAS BIBLIOGRÁFICAS:}

Anais do 20 Congresso de História da Região do Grande ABC. Prefeitura Municipal de São Bernardo do Campo, Secretaria de Educação e Cultura - Departamento de Açôes Culturais, 2000.

ARANTES, Antonio. "Documentos históricos, documentos de cultura. Revista do Patrimônio Histórico e Artístico Nacional, No 22, Brasília, 1987;

CHAUÍ, Marilena. "Política cultural, cultura política e patrimônio histórico. In: CUNHA, Maria Clementina Pereira (org) Direito à Memória: Patrimônio Histórico e Cidadania. SP, DPH, 1992.

FONSECA, Maria. O Patrimônio em Processo - Trajetória da PoliticaFederal de Preservação no Brasil. 2a Ed. Rio de Janeiro, UFRJ, IPHAN, 2005;

KERSTEN, Márcia. Os Rituais de Tombamento e a Escrita da História - Bens Tombados no Paraná entre 1938-1990. Curitiba: Editora UFPR, 2000;

LEITE, Rogério. Contra-usos da Cidade - Lugares e Espaço Público na Experiência Urbana Contemporânea. Campinas: Editora da Unicamp, 2004;

MENEZES, Ulpiano. "Objeto material como documento". In: Patrimônio Cultural: Políticas e Perspectivas. São Paulo, IAB/Condephaat, 1980;

MICELI, Sérgio. "SPHAN: refrigério da cultura oficial". In: Revista do Patrimônio Histórico e Artístico, No 22, Rio de Janeiro, 1987.

RODRIGUES, Marly. Imagens do Passado - A Instituição do Patrimônio em São Paulo, 1969-1987. SP, Ed.Unesp, Imesp, Condephaat, Fapesp, 2000.

TOLEDO, Benedito. Projeto Lorena - Os Caminhos do Mar: Revitalização, Valorização e Uso dos Bens Culturais. PMSBC, PROTUR-SBC, 1975. 